\title{
RENDA BÁSICA INCONDICIONAL PARA A LIBERDADE
}

Jônatas Rodrigues da Silva ${ }^{1}$

\begin{abstract}
Resumo
O presente trabalho é parte de uma pesquisa maior de doutorado, ainda em desenvolvimento, e tem como objetivo conceituar e debater a Renda Básica de Cidadania (RBC). Apresentar propostas concorrentes implementadas em alguns lugares do mundo, entre elas o Programa Bolsa Família (PBF) brasileiro. Explorar a RBC como ferramenta de combate à pobreza e a extrema pobreza no Brasil e de combate a armadilha do emprego e desemprego. A pesquisa versou apresentar o debate histórico de programas de transferência de renda no mundo. As primeiras propostas, locais onde programas de renda condicional e/ou incondicional foram implementados, como ocorreu o debate e como se dá seu financiamento. A metodologia foi a revisão bibliográfica e o estudo de programas existentes em países desenvolvidos e periféricos.
\end{abstract}

Palavras-chave: renda básica; liberdade; transferência de renda; pobreza.

\section{INTRODUÇÃO}

A renda básica é uma utopia realista que apresenta uma perspectiva fora da dualidade ideológica entre socialismo e liberalismo. A ideia é a de uma renda monetária regular, individual e incondicional a todo cidadão, independentemente de sua condição financeira ou de trabalho.

A ideia de uma renda básica não é nova, desde o século XVIII estudiosos pensam a respeito. Mas atualmente com a automação somada às preocupações com os limites ecológicos ao crescimento faz com que o mundo tenha mais interesse pela proposta, argumentam Parijs e Vanderborght (2018).

A ideia de uma renda básica está ligada à de liberdade. Não uma liberdade meramente formal, mas uma liberdade real para todos. A liberdade formal consiste apenas no direito, na não restrição, do acesso a qualquer posição social. Já a liberdade real consiste na remoção de tudo que impede a pessoa de ser livre e de fazer escolhas razoáveis dentro de sua concepção de bem. A liberdade real advém da constante ampliação de capacidades, da equalização de oportunidades que acontece com a oferta de educação de qualidade, saúde, saneamento básico, oportunidades de desenvolvimento, acesso à cultura etc. Quanto mais estes bens sociais chamados de primários por

\footnotetext{
${ }^{1}$ Unesp Araraquara, jonatasrs@yahoo.com.br e 1451204934266281.
} 
Rawls (2016) são ofertados pelo Estado, mais se amplia as capacidades, e consequentemente a liberdade como apregoa Sen (2010).

Nas últimas décadas o mundo viveu uma revolução tecnológica com o computador e a internet, as mudanças foram rápidas e drásticas, porém não proporcionou emancipação dos países e dos cidadãos. A globalização oferta um mercado mundial a pessoas com escassez de habilidades; a automação, a robotização e a inteligência artificial tornam cada vez menor a demanda por trabalho não especializado. Os que têm acesso à tecnologia, que na verdade a desenvolvem e a controlam, ampliam suas capacidades de gerarem receitas, já os países e pessoas periféricas se afastam cada vez mais (BOLTANSKI; CHIAPELLO, 2009).

Parijs e Vanderborght (2018, p. 29), apontam uma realidade que vemos hoje no Brasil: se o nível de remuneração é firmemente protegido por uma salário mínimo e seguro-desemprego, o resultado tende a perdas de emprego maciça; e, se estas proteções são fracas, o resultado são pessoas lutando para sobreviver com salários miseráveis. Eles ainda alertam que com a automação esta realidade tende a aumentar.

Seria a solução para o desemprego o crescimento econômico? É fato que existe uma correlação negativa entre crescimento e desemprego, mas e o limite ecológico para o crescimento? Os impactos no clima estão sendo largamente discutidos nos dias de hoje. Apesar da correlação ser negativa entre crescimento e desemprego, o PIB (Produto Interno Bruto) mundial mais que duplicou nas últimas décadas, porém não foi resolvida a questão do desemprego.

\section{RENDA BÁSICA}

A renda básica é conceitualmente diferente da renda condicional. E ambas podem existir paralelamente. A renda condicional é uma assistência social às pessoas ou famílias, e geralmente está condicionado a uma renda mínima e pré-disposição ao trabalho. No Brasil o PBF (Programa Bolsa Família) é um exemplo de renda condicional vinculado a uma renda mínima e paga sob certas condicionalidades.

A renda básica é individual, é entendida como um direito do cidadão e não da unidade familiar. Não está vinculada a comprovação de renda ou disposição ao trabalho. A ideia não é nova, Parijs e Vanderborght (2018, p. 33) lembram que em 1953 o economista político de Oxford George D. H. Cole já fazia uso do termo neste sentido. Em 1956 o termo também é usado pelo economista 
holandês Jan Tinbergen ao escrever sobre política econômica. E em 1986 a recém fundada Basic Income European Network (BIEN) adota significado semelhante.

A condicionalidade da renda básica está em o beneficiário possuir residência fiscal no Estado. Isto exclui turistas e autoridades diplomáticas (VAN DER VEEN; VAN PARIJS, 2006).

A renda básica não precisa ser necessariamente uniforme, ela pode variar de acordo com a idade ou localização geográfica. Mas ela é um direito de nascença. A variação geográfica poderia funcionar como um instrumento de distribuição de renda. Ela deve ser paga periodicamente.

A renda básica deve ser estável, independente da sua regularidade de pagamento, e pode estar vinculada a algum índice de crescimento econômico como o, produto interno bruto por habitante, o PIB per capita, por exemplo. Esta ideia foi "defendida por Dennis Milner no primeiro plano de renda básica desenvolvido para o Reino Unido em 1920” Parijs e Vanderborght (2018, p. $35)$.

Outro destaque em relação à renda básica é que não faz sentido ela ser hipotecada, os beneficiários não devem poder usar o fluxo futuro da renda como garantia de empréstimos, pois ela não é complemento de renda, mas um nível básico de renda. A legislação deve protegê-la contra expropriações.

Outra indagação é se a renda básica deve ser livre de impostos. Considerando a unidade de tributação a família, e uma tributação progressiva, taxar a renda básica equivale a conceder uma renda menor às pessoas de famílias maiores. Porém se a taxação for na pessoa física, taxar a renda básica é o mesmo que reduzi-la ou eliminá-la a depender de uma determinada renda do cidadão. Administrativamente é mais simples e socialmente mais justo.

A renda básica é um piso incondicional. Apesar da palavra 'básica' ela não é a garantia de uma renda suficiente, ela não define um valor específico. Seu valor estará condicionado a questões fiscais e políticas do país.

Porém, independentemente do valor fixado para a renda básica de um país ela deve ser modesta, não é salutar uma renda que permita uma vida confortável, mas sim um valor que permita ao cidadão colocar em ação seu plano de vida e não se ver obrigado a aceitar ofertas de emprego indesejáveis por medo da fome. Uma renda básica tem potencial para afetar as relações de poder social, de tornar a vida dos nada afortunados mais tolerável, de fazer a sociedade um lugar mais justo, mais almejado por todos. 
A renda básica incondicional não pode ser confundida com assistência pública. Enquanto a primeira a defendemos como um direito do cidadão em participar da riqueza socialmente construída, a segunda visa minimizar o estado de miséria do cidadão.

\subsection{RENDA MONETÁRIA}

A renda básica deve ser paga em dinheiro e não em comida, roupas ou outros itens de necessidade básica. $\mathrm{O}$ valor pago em dinheiro é logisticamente mais rápido e menos custoso com as facilidades de transferências eletrônicas bancárias. Também diminui o uso clientelista da distribuição. Ainda amplia a liberdade de escolha do cidadão de quando e como gastar seus recursos, assim como estimula a economia local.

\subsection{RENDA INDIVIDUAL}

A renda básica deve ser paga individualmente a cada cidadão. Ela não está associada ao pertencimento a um núcleo familiar, é direito individual. Se for paga a crianças ela pode ser custodiada pelo seu responsável legal até uma determinada idade. Ela é paga a ricos e pobres, a quem exerce atividade remunerada e a quem está desempregado, sem distinção.

O financiamento da renda básica pode ser exógeno, advindo de royalties de recursos naturais, ou da tributação da renda, do patrimônio e do consumo das pessoas. Nesta última opção quem mais ganha e quem mais consome acaba por financiar a própria renda básica e a dos demais cidadãos. A junção das duas formas também pode ser adotada.

\subsection{ESTADO E INSTITUIÇÕES}

A renda básica incondicional é um instrumento de liberdade. Apenas o trabalho formal nos setores públicos e privados são remunerados e compõem o cálculo do PIB. Todo trabalho doméstico e social voluntário realizado é ignorado. Milhões de pessoas que realizam trabalhos não remunerados são também agentes do desenvolvimento social e é justo que eles participem da riqueza socialmente construída. A renda básica é uma forma de isto acontecer.

A necessidade de dinheiro para o sustento leva muitos jovens a abandonar a escola precocemente e buscar trabalho remunerado (quase sempre informal). Uma renda básica desarma esta armadilha do subemprego ao ofertar um piso. 
Outra atividade vista com frequência é o empreendedorismo por necessidade e não por vocação. Muitas pessoas empreendem por estarem fora do mercado de trabalho e sem esperança de serem contratadas. Um piso advindo da renda básica nos faz supor que o empreendedorismo por necessidade seria amenizado e o trabalhador estaria mais protegido. Uma renda incondicional permite a ele melhor se qualificar para o trabalho ou para o empreendimento. Também trabalhadores autônomos e cooperados estarão mais protegidos. No médio/longo prazo se verá efeitos positivos no capital humano.

Empregos de alta qualificação e consequentemente melhor renumerados exigem dedicação e atenção diferenciados. Estes em geral são ocupados por pessoas ricas que tiveram a oportunidade de dedicar-se exclusivamente aos estudos e adiar o ingresso no mercado de trabalho. Eles ainda têm a escolha de especializar-se em estágios não remunerados, mas que lhe permitirão serem melhores profissionais no futuro, pois possuem o privilégio de serem sustentados pela família. O pobre, na maioria das vezes se divide entre emprego e escola, e raramente tem acesso a empregos de alta qualificação, pois não teve a oportunidade de qualificar-se adequadamente, pois tinha que trabalhar para prover o próprio sustento. O ciclo da discrepância de renda permanece. A renda básica poderia permitir ao jovem periférico adiar sua entrada no mercado de trabalho e melhor qualificar-se almejando empregos de alta qualificação e remuneração.

A primeira infância tem papel decisivo na vida das crianças (FREIRE, 2019) e uma renda básica daria aos pais a escolha de trabalharem meio período para se dedicarem à educação dos filhos pequenos nos primeiros anos da vida deles.

A segurança da renda básica permite que as pessoas possam ter mais tempo para decidir ou mesmo se arrepender e dar um passo atrás em suas carreiras. Não é incomum pesquisas apontarem que trabalhadores estão infelizes em suas atividades profissionais, mas ao mesmo tempo presos nela por não poderem abrir mão da renda do trabalho para se dedicar a encontrar o que de fato lhes motiva. A renda básica permite às pessoas buscar aquilo que elas realmente gostam de fazer.

\section{METODOLOGIA}

A investigação científica tem por objetivo formular leis ou teorias que permitam explicar fenômenos naturais ou sociais. O conhecimento científico é uma construção inacabada. Para um fenômeno específico pode haver teorias fortes e fracas. Existe um progresso na ciência que faz uso 
de ferramentas que permitem melhores observações e raciocínio mais bem fundamentado (RICHARDSON, 2017).

O método é o caminho utilizado para se chegar a determinado resultado. E a metodologia consiste nos instrumentos adotados, as regras definidas, ao longo do caminho pelo pesquisador. Ela é regular, definida e deve ser passível de repetição.

Toda pesquisa parte de determinados pressupostos que fundamentam o pensar do pesquisador. Estes pressupostos, segundo Richardson (2017, p. 25), são as bases do trabalho científico. São necessários, pois identificam a visão do pesquisador em relação ao homem, à sociedade. Suas perspectivas epistemológicas que serão utilizadas na pesquisa. Estas orientarão a escolha do método e das metodologias utilizadas na pesquisa.

A análise construtivista, que tem suas bases em Immanuel Kant, diz que a pesquisa também é um produto dos valores do pesquisador e não pode ser independente dele. Mertens (2003) citado por Richardson (2017), afirma que toda investigação é carregada de valores.

Uma pesquisa científica é movida por um objetivo, os métodos e as metodologias utilizadas pelo pesquisador são meios para o fim e não uma primazia de um em detrimento ao outro. Inclusive eles podem ser usados conjuntamente.

Nosso objetivo neste trabalho é apresentar a renda básica como instrumento para a liberdade e nossa pesquisa faz uso de um método qualitativo com caráter indutivo.

O problema que norteia esta pesquisa parte da hipótese que a carência financeira é um impedimento para a liberdade.

Nossa metodologia consiste nas seguintes etapas: i) definir o conceito de renda básica na literatura; ii) debater o conceito de liberdade; iii) construir a ideia de desenvolvimento como uma ampliação das liberdades substantivas e; iv) mostrar como a renda básica pode ser um instrumento utilizado para a ampliação de liberdades.

“A pesquisa é um processo de estabelecer postulados para serem aprimorados ou mudados por outros mais sólidos” (CRESWELL, 2000 citado por RICHARDSON, (2017, p. 33)).

Nas ciências naturais os dados consistem na observação empírica. Nas ciências sociais os dados estão carregados de significados não observáveis, sendo necessário interpretação e compreensão associados ao contexto. É um erro a simples conclusão reduzida aos dados observáveis. 


\section{ALTERNATIVAS À RENDA BÁSICA}

Obviamente que existem alternativas à renda básica e a intenção aqui é apresentar e pontuar algumas delas.

\subsection{DOTAÇÃO BÁSICA:}

A renda básica é uma renda regular. A dotação básica é um valor pago uma única fez no início da vida adulta. Proposta inicialmente apresentada por Thomas Paine (1796). Outros pensadores como: James Tobin em 1968, Haveman em 1988 e Bruce Ackeman e Anne Alstott em 1999 também defenderam o pagamento universal de um subsídio (VAN PARIJS; VANDERBORGHT, 2018).

A dotação básica assim como a renda básica é paga incondicionalmente a todo cidadão. A dotação básica poderia ser investida e convertida em renda básica com cálculos atuariais. O problema é que teria que se estimar os anos do benefício tendo como parâmetro a expectativa de vida das pessoas, porém pessoas vivem mais ou menos da expectativa média. Também a dotação básica seria paga na vida adulta equalizando as oportunidades. Mas o desenvolvimento dependente da liberdade (SEN, 2010) e a primeira infância é a fase mais fértil da vida para o desenvolvimento de capacidades. Uma dotação paga somente na vida adulta mitiga a oferta de possibilidades na infância, proporcionando uma vantagem às famílias ricas que tem condições de ofertar aos seus filhos atenção, qualidade escolar, cultura, orientação e demais condições que são fundamentais à criança.

A renda básica protege a liberdade ao longo da vida e tem potencial para uniformizar oportunidades de desenvolvimento cognitivo nas crianças.

Sendo a renda básica fluxo contínuo e a dotação básica aporte único, mesmo que com valores atuarialmente iguais, a dotação única está sujeita a euforia e imaturidade da juventude, podendo o jovem fazer uma aposta e perder todo o dinheiro. A renda básica é mais compatível com a ideia de liberdade e oportunidades ao longo de toda a vida.

\subsection{IMPOSTO DE RENDA NEGATIVO:}


O economista Milton Friedman (1912/2006), ganhador do Nobel de economia em 1976, é o mais conhecido defensor do imposto de renda negativo. Sua proposta tem como objetivo mitigar a pobreza (FRIEDMAN, 2019) e é direcionada ao cidadão pobre. Alíquotas de subsídio poderiam ser progressivas assim como as alíquotas de imposto acima do limite de isenção. Se estabeleceria um piso no qual a renda líquida de ninguém poderia ser inferior. $\mathrm{O}$ valor do piso dependeria da capacidade contributiva da sociedade. O cidadão sem renda, e que não tivesse dedução, receberia o piso.

Tomemos como exemplo um limite de isenção por pessoa de \$1.000. Toda renda acima deste valor após as deduções paga imposto de renda federal. Ainda como exemplo, definamos uma alíquota de $50 \%$ tanto para o imposto de renda pago quanto para o imposto de renda negativo (o subsídio recebido). Se um trabalhador após as deduções tem renda tributável de \$100, ela pagaria $50 \%$, portanto $\$ 50$ de imposto de renda. Seu rendimento líquido seria de \$1050. Outro trabalhador que tivesse renda de $\$ 900$, faria jus a $50 \%$ da diferença do limite de isenção: $\$ 1000-\$ 900=$ $\$ 100$, e $50 \%$ de $\$ 100$ são $\$ 50$. Assim o trabalhador teria adicionado aos seus rendimentos $\$ 50$ e receberia um total de $\$ 950$.

Uma pessoa sem rendimento algum recebe o piso que corresponde a $50 \%$ do valor de isenção: $\$ 500$.

As propostas de imposto de renda negativo são variadas, algumas se assemelham muito a da renda básica ao considerarem o cidadão como unidade de distribuição, e não exigir disposição ao trabalho. Outras propostas exigem disposição ao trabalho de pessoas fisicamente e mentalmente aptas, e há propostas que consideram a família como núcleo de tributação e não o indivíduo.

Consideramos a proposta de imposto de renda negativo interessante como ferramenta de mitigação da pobreza, mas falha em proporcionar liberdade substantiva ao cidadão. Se ela exigir disposição ao trabalho ela não permitirá a ociosidade criativa (SENGE, 2009). Um outro problema menor, que acreditamos ser facilmente administrado com as transações eletrônicas, é seu caráter expost, o pagamento do subsídio após as comprovações legais de renda. Mas ele peca ao ser uma política de distribuição de renda ao pobre, ao estigmatizar o pobre.

A renda básica é uma proposta que divide as vantagens da vida em sociedade, ela não é somente uma política de combate à pobreza, mas um entendimento radical que todo cidadão tem por direito parte da riqueza socialmente construída. Ela tem potencial para conceder de fato a liberdade para todo cidadão desenvolver suas capacidades. 


\subsection{CRÉDITO FISCAL POR REMUNERAÇÃO RECEBIDA:}

É uma proposta que concentra a atenção nos pobres que trabalham. É um crédito concedido ao trabalhador mal remunerado.

Atualmente os EUA fazem uso deste sistema, o que eles chamam de EITC (earned income tax credit). Ele foi proposto a primeira vez em 1970 pelo senador Russell B. Long do partido Democrata como alternativa ao Plano de Assistência Familiar do presidente Nixon (1969-74). O governo Clinton (1993-2001) o ampliou significativamente durante seu governo. Em 2013 ele abrangia aproximadamente 27 milhões de pessoas (VAN PARIJS; VANDERBORGHT, 2018).

Assim como o imposto de renda negativo o EITC concede crédito fiscal. Ele depende da renda apenas do trabalho e não da renda total. A unidade relevante é a família e não o cidadão, o que traz desincentivos ao trabalho em casais casados.

A partir da década de 1990 países da OCDE (Organização para a Cooperação e Desenvolvimento Econômico) adotaram modelos semelhantes. Na França existe o Prime d'activeté (prêmio de atividade) e no Reino Unido o Bristish workin tax credit (crédito fiscal de trabalho britânico).

O EITC é pago ex-post e meses após o salário qualificado fazer jus. O que o torna paradoxal como um programa de combate à pobreza, pois a fome não pode esperar. Ele não protege as famílias da perda de renda.

O EITC não protege o desempregado e parece se alinhar à visão comum que se mostra solidária a quem trabalha, considerando o desempregado vagabundo.

\subsection{PROGRAMA BOLSA FAMÍLIA:}

O PBF (Programa Bolsa Família) é um programa de renda condicional brasileiro criado no governo do presidente Lula (2003) por meio da lei 10.835/2004. O programa unificou quatro programas de transferência de renda existentes à época: o Bolsa Escola, o Bolsa Alimentação, o Auxílio Gás e o Cartão Alimentação (SUPLICY, 2006).

O PBF considera a família como unidade de distribuição e paga o máximo de 5 benefícios por família e impõe condicionalidades. Tem direito a receber o benefício famílias pobres ou em extrema pobreza com renda per capita mensal de até $\mathrm{R} \$ 178,00$. As famílias têm direito ao 
benefício desde que em sua composição haja mulheres grávidas ou crianças e/ou adolescentes entre 0 e 17 anos $^{2}$.

Condicionalidades também são exigidas para a continuidade do benefício. Em relação à educação das crianças e adolescentes as famílias devem: matricular as crianças e adolescentes de 6 a 17 anos na escola; garantir a frequência escolar mensal mínima de 85\% para as crianças de 6 a 15 anos; garantir a frequência escolar mensal mínima de 75\% para os adolescentes de 16 e 17 anos que recebem o BVJ (Benefício Variável Jovem). O BVJ é pago à família com renda per capita mensal de até $\mathrm{R} \$ 178,00$ e que tenha adolescentes com 16 e 17 anos. O valor é de R \$48,00 por adolescente e paga-se no máximo dois BVJ. Informar à escola sempre que algum motivo impedir o aluno de ir às aulas; manter atualizadas as informações de escola das crianças e adolescentes no Cadastro Único. As famílias devem: levar as crianças de até 7 anos para serem vacinadas conforme o calendário de vacinação do Ministério da Saúde; levar as crianças de até 7 anos para serem pesadas e medidas de maneira a terem acompanhados o seu crescimento e desenvolvimento; levar as gestantes a participarem do pré-natal.

O programa tem um alto custo de focalização: o custo para identificar e pagar as famílias beneficiárias. Ele também desestimula a unidade familiar a limitar o número de benefícios a um núcleo familiar. Este limite se torna um estímulo ao desmembramento familiar. O programa também desestimula o trabalho, pois qualquer aumento mínimo da renda familiar faz cessar ou diminuir o benefício. Ele taxa em $100 \%$ qualquer renda adicional.

Também o PBF estigmatiza ao ser um programa destinado ao pobre e não um direito de cidadania.

Ao não ser universal e depender da capacidade estatal em identificar as famílias pobres o PBF incorre no grave risco de deixar famílias de fora do programa por não as identificar. Também está sujeito ao clientelismo político.

\section{QUADRO 1 - Propostas concorrentes à da Renda Básica}

\begin{tabular}{|l|l|l|l}
\multicolumn{1}{|c}{ Nome } & \multicolumn{1}{c}{ Idealizador } & \multicolumn{1}{c}{ Característica } & A quem é destinado \\
\hline \multirow{2}{*}{ Dotação básica } & $\begin{array}{l}\text { Thomas Paine, 1796; } \\
\text { James Tobin, 1968; }\end{array}$ & Valor pago uma & \\
& $\begin{array}{l}\text { Haveman, 1988; } \\
\text { Bruce Ackeman e }\end{array}$ & a vida adulta. & \\
& &
\end{tabular}

\footnotetext{
${ }^{2}$ Fonte: Ministério do Desenvolvimento Social.
} 


\begin{tabular}{|c|c|c|c|}
\hline & Anne Alstott, 1999. & & \\
\hline $\begin{array}{l}\text { Imposto de renda } \\
\text { negativo }\end{array}$ & $\begin{array}{l}\text { Milton Friedman, } \\
1976 .\end{array}$ & $\begin{array}{l}\text { Subsídio à renda } \\
\text { abaixo de um } \\
\text { determinado valor. }\end{array}$ & Ao pobre. \\
\hline $\begin{array}{l}\text { Crédito fiscal por } \\
\text { remuneração } \\
\text { recebida }\end{array}$ & $\begin{array}{l}\text { Senador Russel B. } \\
\text { Long, } 1970\end{array}$ & $\begin{array}{l}\text { Crédito adicional ao } \\
\text { trabalhador que } \\
\text { recebe abaixo de um } \\
\text { determinado piso. }\end{array}$ & $\begin{array}{l}\text { Ao pobre com } \\
\text { trabalho formal. }\end{array}$ \\
\hline $\begin{array}{l}\text { Programa bolsa } \\
\text { família }\end{array}$ & $\begin{array}{l}\text { Presidente Lula, } \\
2003 \\
\text { Senador Eduardo } \\
\text { Suplicy, } 2003\end{array}$ & $\begin{array}{l}\text { Famílias com renda } \\
\text { per capita de até R\$ } \\
178,00 \text { que se } \\
\text { comprometem a } \\
\text { manter os filhos na } \\
\text { escola e a vaciná-los. }\end{array}$ & $\begin{array}{l}\text { Ao pobre com filhos } \\
\text { de até } 17 \text { anos. }\end{array}$ \\
\hline
\end{tabular}

Fonte: elaborado pelo autor

\section{DA SEGURIDADE SOCIAL À RENDA BÁSICA}

A lei da Seguridade Social (1935) do presidente americano Franklin Roosevelt foi a primeira, e garantia um seguro para a velhice, seguro-desemprego e um programa de assistência pública às famílias com filhos. Tinha financiamento federal e foi implementado em nível estadual. Em 1964 sob a presidência de Lyndon Johnson foi criado um programa que oferta cupons de alimentos, o SNAP (Supplemental Nutrition Assistance Program). Ele foi criado dentro do sistema de "guerra à pobreza" e é direcionado aos adultos pobres disponíveis ao trabalho, mas sem emprego. Ele permite a estas pessoas comprarem comida em determinados estabelecimentos.

Em 1948 o Reino Unido aprovou a lei de Assistência Nacional intitulada "Social Insurance and Allied Services". A lei ofertava assistência em dinheiro às famílias pobres por tempo indeterminado. A quantia deveria ser suficiente para atender às necessidades da família, e seus membros em condições físicas devem estar registrados como elegíveis a um emprego.

Tanta a oferta de cupons de alimentos como a Social Insurance and Allied no Reino Unido estão em vigor ainda hoje. 
No século XX muitos programas semelhantes surgiram na Europa. Na Suécia em 1957. Na Dinamarca e na Alemanha em 1961. Os Países Baixos em 1963. Noruega em 1964. Bélgica em 1974 e Irlanda em 1975. Na França em 1988 (VAN PARIJS; VANDERBORGHT, 2018).

O Japão tem a lei de Proteção à Subsistência de 1950. De acordo com a lei todo cidadão carente tem direito a assistência pública desde que disponível ao trabalho.

Estes programas possuem graus variados de generosidade e as condições variam muito em cada país e mesmo dentro de um mesmo país. Porém todos têm em comum a exigência de comprovação de carência e disponibilidade ao trabalho dos fisicamente capazes.

$\mathrm{Na}$ América Latina, muitos países possuem algum programa de transferência de renda como destacava o Banco Mundial (2015): México, Chile, Paraguai, Bolívia, Uruguai, Argentina e Brasil são alguns exemplos (PASE et al., 2017):

QUADRO 2 - Alguns programas de transferência de renda em vigor atualmente e suas condicionalidades.

\begin{tabular}{|c|c|c|}
\hline NOME DO PROGRAMA & PAÍS E ANO & CONDICONALIDADES \\
\hline $\begin{array}{l}\text { SNAP (Supplemental } \\
\text { Nutrition Assistance } \\
\text { Program) }\end{array}$ & EUA, 1964 & $\begin{array}{l}\text { Pobres disponíveis ao } \\
\text { trabalho. }\end{array}$ \\
\hline $\begin{array}{l}\text { Social Insurance and } \\
\text { Allied Services }\end{array}$ & Reino Unido, 1948 & $\begin{array}{l}\text { Pobres disponíveis ao } \\
\text { trabalho. }\end{array}$ \\
\hline Proteção à Subsistência & Japão, 1950 & $\begin{array}{l}\text { Pobres disponíveis ao } \\
\text { trabalho. }\end{array}$ \\
\hline Progreso (Prospera) & México, 1997 & $\begin{array}{l}\text { Famílias em extrema } \\
\text { pobreza com renda per } \\
\text { capita de até } 1,79 \text { dólares } \\
\text { (rurais) e 2,34 dólares } \\
\text { (urbanas). }\end{array}$ \\
\hline Chile Solidario & Chile, 2002 & $\begin{array}{l}\text { Famílias em extrema } \\
\text { pobreza. }\end{array}$ \\
\hline Tekoporã & Paraguai, 2005 & $\begin{array}{l}\text { Baixa qualidade de vida } \\
\text { medidos pelo Índice de } \\
\text { Qualidade de Vida do }\end{array}$ \\
\hline
\end{tabular}




\begin{tabular}{|l|l|l|}
\hline & & $\begin{array}{l}\text { governo local. } \\
\text { Crianças e adolescents } \\
\text { Bono Juancito Pinto (BJP) }\end{array}$ \\
\hline & Bolívia, 2006 & $\begin{array}{l}\text { Pobreza extrema e a } \\
\text { vulnerabilidade }\end{array}$ \\
\hline Cercanias & Uruguai, 2005 & social da família. \\
\hline Asignación Universal por & Argentina, 2009 & Crianças e adolescentes \\
Social (AUH) & menores de 18 anos. \\
\hline Programa Bolsa Família & Brasil, 2003 & Famílias com filhos pobres \\
\hline
\end{tabular}

Fonte: elaborado pelo autor

\subsection{A SEMENTE DA RENDA BÁSICA}

O britânico Thomas Paine (1737-1809) foi um intelectual revolucionário que defendeu uma justiça agrária (1796) no legislativo francês. Paine era destaque tanto nos movimentos revolucionários franceses como americano. Sua proposta caminhou em sentido contrário da assistência pública e da seguridade social. Propôs a criação de um fundo nacional e o pagamento de uma dada quantia a todo cidadão ao completar 21 anos mais pagamentos anuais por toda a vida aqueles com 50 anos ou mais anos.

O valor pago inicialmente era suficiente para um jovem "comprar uma vaca e utensílios para cultivar alguns hectares de terra" (VAN PARIJS; VANDERBORGHT, 2018, p. 120).

A justificativa moral de Paine é cristã: que a terra é propriedade comum da humanidade. Ele também argumenta que a terra em seu estado natural e sem melhorias é propriedade comum, e que o homem tem por direito apenas às melhorias advindas do seu trabalho de cultivo. Por isso é justo o pagamento de um imposto à sociedade pelo uso privado da terra.

A proposta de Paine não foi de uma renda básica contínua, mas foi incondicional, paga a ricos e pobres, a cada cidadão e não a um núcleo familiar, sem comprovação de renda ou disponibilidade ao trabalho tendo como argumento que a terra é propriedade da humanidade.

Em 1797, ano seguinte à proposta de Thomas Paine, o inglês Thomas Spence (1750-1814) foi mais audacioso e propôs uma renda básica incondicional e individual paga a todos, do rico ao pobre, do recém-nascido ao idoso. Sua proposta dizia que todas as terras e casas deveriam ser 
administradas por uma câmara de mulheres; o uso leiloado e os rendimentos cobrir os gastos públicos e o excedente repartido justamente e igualmente a todos sem distinção.

Argumenta Spence que o excedente é direito de todo ser humano em uma sociedade civilizada. Que as matérias-primas naturais são de propriedade comum e que pessoas são privadas ao se permitir o uso privado e sua melhoria.

A diferenças da proposta de Spence em relação à de Paine está no financiamento. Paine taxaria apenas o uso da terra, enquanto Spence a terra, a matéria-prima, imóveis e mesmo as melhorias.

Ambos os planos foram debatidos no congresso e rejeitados.

\section{A IDEIA DE LIBERDADE}

O economista indiano Amartya Sen (1933/hoje) afirma que o mundo atual nega liberdades elementares a muitas pessoas. Que a ausência de liberdades substantivas está diretamente ligada a pobreza econômica. O não acesso a uma alimentação saudável, a água potável; somados a ausência ou carência de serviços públicos básicos como educação, segurança e assistência médica e social é uma negação de liberdade, é um impedimento de participação da vida política e civil em uma sociedade.

Sen (2010) salienta que muitos usam as palavras desenvolvimento e crescimento como sinônimos. Porém o crescimento econômico, que implica em desenvolvimento industrial, avanço tecnológico e aumento da renda pessoal é diferente de desenvolvimento. O enfoque do desenvolvimento está na ampliação das liberdades sociais e econômicas como a melhoria nos serviços de educação e saúde e maiores direitos civis. Obviamente o progresso tecnológico contribui, mas é a consequência e não a causa última.

Assim definimos desenvolvimento, como a remoção de tudo que priva a liberdade.

O desenvolvimento deve ser buscado como ampliação da liberdade. Não é possível se falar em liberdade quando há privação, sendo a pobreza uma das principais, senão a principal, privação da liberdade. Também privam a liberdade governos tiranos, ausência de serviços públicos como saneamento básico, por exemplo, tirania, intolerâncias como o racismo e a homofobia entre tantas outras coisas.

Só existe progresso com aumento das liberdades (SEN, 2010). 


\section{QUADRO 3 - Crescimento versus Desenvolvimento}

\begin{tabular}{ll}
\hline Características do CRESCIMENTO: & Características do DESENVLVIMENTO: \\
\hline Aumento do PIB; & $\begin{array}{l}\text { Ampliação das liberdades sociais e } \\
\text { econômicas; }\end{array}$ \\
\hline Crescimento industrial; & Ampliação de serviços públicos; \\
\hline Aumento da renda pessoal; & Educação de qualidade para todos; \\
\hline Desenvolvimento industrial; & Melhorias constantes na saúde; \\
\hline Avanço tecnológico. & Mais pessoas assistidas com saneamento básico \\
& e água potável; \\
\hline & Equidade de oportunidades; \\
\hline & Liberdade políticas; \\
\hline & Liberdades de trocas e transações econômicas.
\end{tabular}

Fonte: elaborado pelo autor com referência em (SEN, 2010)

\subsection{EQUALIZAR OPORTUNIDADES É DESENVOLVIMENTO.}

Perceber a ideia de desenvolvimento como um processo de expansão das liberdades substantivas é fundamental para entendermos desenvolvimento. Liberdades econômicas, sociais e políticas precisam ser ampliadas constantemente. O desenvolvimento consiste na ampliação destas liberdades (SEN, 2010).

O economista Fernando Schuler (2020) escrevendo ao jornal Folha de S. Paulo em 02/04/2020 afirma em seu artigo que "livrando as pessoas da urgência econômica, elas poderão dizer "não" às múltiplas formas de humilhação social e darão um novo significado à ideia de liberdade individual".

O Brasil precisa converter seu programa de renda mínima, o PBF, em um programa de renda básica. E a simpatia pela ideia ganhou força com o isolamento social imposto pela Covid-19 que escrachou a necessidade de prover recursos que permitam às pessoas viveram com a mínima dignidade.

A pandemia impulsionou alguns debates e levou o ex-senador da república e hoje vereador na cidade de São Paulo, Eduardo Suplicy, um senhor de 78 anos, em entrevista à jornalista 
Fernanda Mena da Folha de S. Paulo (2020) a dizer que "tudo indica que vou viver para ver a renda básica implementada". A renda básica é defendida pelo vereador há mais de três décadas.

A busca pela liberdade envolve processos que promovam oportunidades, e a renda básica é uma das ferramentas que amplia a liberdade de escolha das pessoas.

Ainda é preciso entender a liberdade não apenas como a ausência de coerção ou privação, não apenas procedimental como defendem os libertários, mas como a oferta das condições substantivas necessárias, e estas passam necessariamente pela educação, pela saúde (e saneamento básico é uma condição primária para se ter saúde, assim como acesso a vacinas), por uma alimentação balanceada e equilibrada, por oferta de cultura, por moradia digna. Acesso a água potável.

Uma renda básica incondicional é coerente com a defesa da liberdade. Da liberdade real e não de uma liberdade meramente formal. É interpretar o conceito de liberdade como a capacidade de fato de fazer o que se deseja.

Porém, defender a justiça distributiva não significa querer equalizar os recursos. Como argumenta Rawls (2016) em seu segundo princípio de justiça, desigualdades sociais e econômicas podem ser consideradas justas quando operam no sentido do maior benefício aos membros menos favorecidos da sociedade.

É preciso formular com cautela a concepção de justiça distributiva como liberdade real, pois não é justo a concessão de uma renda básica que permita se viver tranquilamente na ociosidade, mas também não é, uma que impossibilite que a pessoa escolha seu plano de vida valorando as concepções de bem que ela possui.

As pessoas se apropriam de maneira bastante desigual dos recursos naturais e tecnológicos de acumulação de capital ao longo de gerações. A renda básica visa garantir uma apropriação mais justa de tudo aquilo que é conhecimento herdado de gerações, e não apenas de uma ou algumas pessoas em específico.

\section{CONSIDERAÇÕES FINAIS}

A Covi-19, uma infeção causada por coronavírus, provocou uma pandemia mundial em 2020. O problema trouxe para a agenda política brasileira o conceito de Renda Básica. 
No Brasil quase metade dos trabalhadores são informais, e o isolamento social das pessoas somado ao fechamento dos estabelecimentos comerciais não essenciais jogou luz a um grande problema conhecido e negligenciado pelo estado brasileiro: a falta de assistência social aos mais carentes.

Frente ao problema emergencial a câmera dos deputados aprovou por unanimidade em 26/03/2020 um auxílio emergencial com duração de três meses, que posteriormente foi prorrogado por mais dois meses, no valor de $\mathrm{R} \$ 600,00$ por trabalhador e limitado há dois auxílios por núcleo familiar.

O cadastro para se declarar elegível ao recebimento da RBE é realizado em um aplicativo criado para este fim e disponibilizado pelo governo federal para as plataformas IOS e Android. O download e envio dos dados é realizado sem a necessidade de a pessoa ter crédito em seu aparelho celular. Este cadastro se faz necessário para as pessoas que não possuem cadastro no CadÚnico, estas, além dos beneficiários do PBF, já são automaticamente elegíveis. Os beneficiários com conta nos bancos Caixa Econômica Federal e/ou Banco do Brasil recebem o benefício direto na conta.

O auxílio emergencial favorecesse profissionais sem carteira assinada, autônomos, MEIs (Micro Empresário Individual), desempregados e contribuintes individuais da previdência social.

Não são elegíveis ao recebimento do auxílio famílias com renda superior a três salários mínimos ou com renda per capita acima de $\mathrm{R} \$ 522,50$.

Também não são beneficiários da renda emergencial desempregados recebendo seguro desemprego; aposentados e pensionais, beneficiários do BPC (Benefício e Prestação Continuada) e funcionários públicos.

A proposta teve aprovação do senado federal em 30/03/2020.

A renda básica é uma ferramenta eficiente para a ampliação da liberdade. Uma renda monetária individual e permanente que permita ao cidadão ter acesso àquilo que ele valora. Hardt e Negri (2016, p. 341) afirmam que as ideologias dominantes de hoje não permitem, ou tornam difícil, enxergar o comum. A renda básica é uma maneira de partilhar o comum socialmente construído. Uma renda mínima garantida e paga a todos independente do trabalho, defendem os autores, poderia proporcionar liberdade de tempo.

O capitalismo contemporâneo é orgânico, mas a riqueza produzida socialmente tem sido concentrada nas mãos de poucos e não partilhada. Uma renda básica faz justiça ao partilhar esta riqueza socialmente construída aos membros da sociedade política estabelecida. 
O trabalho hoje é em grande parte biopolítico, o trabalhador é instrumento para a geração de riqueza ao produzir conhecimento através de imagens, afetos e relações sociais. Compartilhamos linguagens, práticas sociais e modos de sociabilidade. Criações comuns que são exploradas financeiramente apenas por alguns. Este valor socialmente construído não se limita a teoria econômica da escassez, pelo contrário, o conhecimento social se amplia com seu uso. São valores sociais construídos nos relacionamentos pessoais e coletivos do dia-a-dia e em redes: sociais, de trabalho e online (HARDT; NEGRI, 2016).

A expropriação de valor no contexto biopolítico é muitas vezes despercebida, são externalidades positivas apropriadas por poucos quando elas pertencem à toda sociedade. A renda básica é uma forma de compartilhar socialmente o que é valor, a riqueza socialmente criada, mas apropriada por poucos. A renda básica permite aos que foram afetados por externalidade negativas na loteria da vida ampliarem a liberdade social e econômica, pois o compartilhamento da riqueza dá a todos oportunidade de escolha, ou seja, maior liberdade de conduzir suas vidas não por não terem o mínimo para a sobrevivência, mas por primazia.

\section{REFERENCIAS}

BOLTANSKI, L.; CHIAPELLO, È. O novo espírito do capitalismo. São Paulo: WMF Martins Fontes, 2009.

FREIRE, P. Pedagogia do oprimido. 69. ed. Rio de Janeiro (RJ): Paz e Terra, 2019.

FRIEDMAN, M. Capitalismo e liberdade. 1. ed. Rio de Janeiro (RJ): LTC, 2019.

HARDT, M.; NEGRI, A. Bem estar comum. 1. ed. Rio de Janeiro (RJ): Record, 2016.

MENA, F. "Tudo indica que vou viver para ver a renda básica implementada", diz Eduardo Suplicy. Disponível em: <https://www1.folha.uol.com.br/mercado/2020/04/tudo-indica-que-vouviver-para-ver-a-renda-basica-implementada-diz-eduardo-suplicy.shtml>. Acesso em: 1 set. 2020.

PASE, H. L. et al. Políticas públicas de transferência de renda na América Latina. Revista de Administração Pública, v. 51, n. 2, p. 312-329, mar. 2017.

RAWLS, J. Uma teoria de justiça. 4. ed. São Paulo (SP): Martins Fontes, 2016.

RICHARDSON, R. J. Pesquisa Social: métodos e técnicas. 4. ed. São Paulo (SP): Atlas, 2017.

SCHÜLER, F. Renda básica lança luz sobre o desafio ético do nosso tempo. Disponível em: $<$ https://www1.folha.uol.com.br/colunas/fernando-schuler/2020/04/renda-basica-lanca-luz-sobre-odesafio-etico-do-nosso-tempo.shtml>. Acesso em: 1 set. 2020. 
SEN, A. K. Desenvolvimento como liberdade. São Paulo (SP): Companhia de Bolso, 2010.

SENGE, P. M. A quinta disciplina: arte e prática da organização que aprende. Rio de Janeiro: Best Seller, 2009.

SUPLICY, E. M. Renda básica de cidadania: a resposta dada pelo vento. Porto Alegre: L\&PM, 2006.

VAN DER VEEN, R. J.; VAN PARIJS, P. A Capitalist Road to Communism. Basic Income Studies, v. 1, n. 1, 28 jan. 2006.

VAN PARIJS, P.; VANDERBORGHT, Y. Renda básica: uma proposta radical para uma sociedade livre e economia sã. São Paulo (SP): Cortez, 2018. 